1. Higham, T. et al. Nature 479, 521-524 (2011).

2. Reimer, P. J. et al. Radiocarbon 51, 1111-1150 (2009).

3. Benazzi, S. et al. Nature 479, 525-528 (2011)

4. Bailey, S. E., Weaver, T. D. \& Hublin, J.-J. J. Hum. Evol. 57, 11-26 (2009).

5. Keith, A. Trans. Proc. Torquay Nat. Hist. Soc. 5, 1-2 (1927).

6. Szmidt, C. C., Brou, L. \& Jaccottey, L. J. Archaeol. Sci. 37, 3320-3337 (2010)

7. Nigst, P. R. in When Neanderthals and Modern Humans Met (ed. Conard, N. J.) 269-304 (Kerns, 2006).

8. Trinkaus, E. Annu. Rev. Anthropol. 34, 207-230 (2005)
9. Kozlowski, J. K. in Rethinking the Human Revolution (eds Mellars, P., Boyle, K., Stringer, C. \& Bar-Yosef, O.) 317-328 (McDonald Inst., 2007).

10.D’Errico, F., Zilhão, J., Julien, M., Baffier, D. \& Pelegrin, J. Curr. Anthropol. 39, S1-S44 (1998).

11.D’Errico, F. Evol. Anthropol. 12, 188-202 (2003).

12. Mellars, P. Evol. Anthropol. 14, 12-27 (2005).

13.Soares, P. et al. Curr. Biol. 20, R174-R183 (2010)

14.Azoury, I. Ksar Akil, Lebanon (Br. Archaeol. Rep., 1986).

15.Ambrose, S. H. J. Archaeol. Sci. 25, 377-392 (1998).

16.Svoboda, J. A. in Rethinking the Human Revolution

(eds Mellars, P., Boyle, K., Stringer, C. \& Bar-Yosef, O.)

329-339 (McDonald Inst., 2007).

17. Mellars, P. Evol. Anthropol. 15, 167-182 (2006).

\title{
Europa awakening
}

\section{Brines percolating in the icy crust of Jupiter's moon Europa may be responsible for the satellite's enigmatic chaotic terrains. A new model predicts that one such terrain is currently forming over shallow subsurface water. SEE LETTER P.502}

\section{LASZLO P. KESZTHELYI}

$\mathrm{O}$ n page 502 of this issue, Schmidt and colleagues ${ }^{1}$ posit that Europa, one of the four large satellites of Jupiter, is currently geologically active* ${ }^{\star}$ This result could profoundly affect the future exploration of Europa, which is consistently NASA's top target for robotic exploration in the outer Solar System ${ }^{2,3}$. With an ocean of liquid water roughly twice the volume of Earth's oceans lying beneath an icy crust, Europa is the most obvious place to search for extraterrestrial life $^{2,3}$. Although the ultimate goal of exploring Europa is to sample the ocean, the next space mission is focused on gauging the thickness of the frozen carapace that another mission will need to pierce. The overwhelming majority of researchers agree that the ice crust is approximately $20 \pm 10$ kilometres thick ${ }^{4-6}$; however, the appearance of an unresolved controversy is maintained by a handful of studies that suggest the crust is only a few kilometres thick ${ }^{7,8}$. This debate has remained frozen by the absence of new observational constraints since the demise of the Galileo orbiter in 2003.

Schmidt and colleagues ${ }^{1}$ shake this impasse by coupling insights from terrestrial glacial processes with refined analyses of the Galileo data. The authors did not discover a place on Earth that mimics the alien conditions of Europa. Instead, they built on a new recognition of the role of brines (salt water) along the margins of the Antarctic ice sheet and improved understanding of the movement of water and ice in response to subglacial volcanic eruptions. Specifically, salt water can flow through fractures in ice, transporting significant volumes of both water and dissolved minerals over large distances. When

*This article and the paper ${ }^{1}$ under discussion were published online on 16 November 2011

these brines do eventually freeze, material has been redistributed and the stresses within the ice have been rearranged. Also, an investigation ${ }^{9}$ of subglacial eruptions in locations such as Iceland showed that the stresses around a small body of liquid water within a large body of ice serve to keep the liquid confined in a discrete, subsurface, lens-shaped region.

Combining these ideas, Schmidt et al. ${ }^{1}$ propose a model for the formation of 'chaos terrain' on Europa. A chaos is a discrete patch of the surface consisting of disrupted crustal blocks that

"This study could well be a blueprint for how brealthroughs in planetary science will continue even in a period of fiscal austerity and fewer new data." have a superficial resemblance to icebergs calving into the sea. The model relies on a plume of warm, convecting, pure ice bringing heat up to a layer of salty ice that has a lower melting temperature. When this salty ice melts, there is a reduction in its volume and the surface collapses. The resulting fractures are filled with brine that eventually freezes and expands, uplifting the matrix between large collapsed crustal blocks. This model fits the available observations better than previous models. Most interestingly, it suggests that the chaos at a surface feature on Europa known as Thera Macula, which is about 100 kilometres in diameter, is currently forming over liquid brine existing within a few kilometres of the surface.

The authors' suggestion ${ }^{1}$ that Europa has internal processes that are active today is important for many different reasons. Although previous studies have shown that the surface of Europa is geologically young, with an average age of around 30 million to
70 million years old ${ }^{10}$, current geological activity has not been detected ${ }^{11}$. If active, Europa would be in the exclusive company of Earth, Jupiter's moon Io and Saturn's moon Enceladus. The activity observed on Mars, Saturn's moon Titan and Neptune's moon Triton seems to be driven by solar energy rather than internal heat.

Furthermore, Schmidt and colleagues' study provides an important target for future missions to Europa. If their model is correct, Thera Macula should have changed markedly in the decades between Galileo and the next mission to Europa. Such changes would mark a location that has a pocket of water at a depth that is much more accessible than the underlying main ocean.

As a final note, this study could well be a blueprint for how breakthroughs in planetary science will continue even in a period of fiscal austerity and fewer new data. There is still much to be done to extract information from older data and then convert that into scientific understanding. For example, the addition of topographic information to two-dimensional surface images and the spectroscopic identification of minerals have often proved invaluable in choosing between different models for subsurface processes. However, because the derivation of topography and mineralogy from the available data is still complex and time-consuming, a vast treasure trove has yet to be mined.

Similarly, the days of making discoveries by simply visually comparing features on Earth with extraterrestrial ones are probably drawing to a close. Instead, as in this study, it will be essential to understand fundamental processes on Earth and then extrapolate to how these processes interact in an alien setting. Thus, in many ways, Schmidt and colleagues' work could well be illuminating the path for future exploration of not just Europa but the wider Solar System.

Laszlo P. Keszthelyi is at the Astrogeology Science Center, US Geological Survey,

Flagstaff, Arizona 86001, USA.

e-mail:laz@usgs.gov

1. Schmidt, B. E., Blankenship, D. D., Patterson, G. W. \& Schenk, P. M. Nature 479, 502-505 (2011).

2. National Research Council New Frontiers in the Solar System: An Integrated Exploration Strategy (National Academies Press, 2003).

3. National Research Council Vision and Voyages for Planetary Science in the Decade 2013-2022 (National Academies Press, 2011).

4. Pappalardo, R. T. et al. Nature 391, 365-368 (1998)

5. Turtle, E. P. \& Pierazzo, E. Science 294, 1326-1328 (2001).

6. McKinnon, W. B. Geophys. Res. Lett. 26, 951-954 (1999).

7. Greenberg, R. G. et al. Icarus 141, 263-286 (1999)

8. Hoppa, G. V., Tufts, B. R., Greenberg, R. \& Geissler, P. E. Science 285, 1899-1902 (1999).

9. Bjornsson, H. Glob. Planet. Change 35, 255-271 (2002)

10.Zahnle, K., Schenk, P., Levison, H. \& Dones, L. Icarus 163, 263-289 (2003).

11.Phillips, C. B. et al. J. Geophys. Res. 105, 22579-22598 (2000) 